\title{
Characterisation of recombinant glycosylation variants of insulin-like growth factor binding protein-3
}

\author{
S M Firth and R C Baxter
}

Kolling Institute of Medical Research, Royal North Shore Hospital, St Leonards, New South Wales 2065, Australia

(Requests for offprints should be addressed to S M Firth)

\begin{abstract}
There are three potential $N$-glycosylation sites in the non-conserved central region of the insulin-like growth factor binding protein-3 (IGFBP-3) sequence $\left(\mathrm{N}^{89} \mathrm{AS}, \mathrm{N}^{109} \mathrm{AS}, \mathrm{N}^{172} \mathrm{FS}\right)$. IGFBP-3 exists as two glycoforms which reduce to a single form on enzymatic deglycosylation. To determine the functional significance of the carbohydrate chains, the $N$-glycosylation sites were mutated singly and in combinations by substituting Asn residues with Ala. Each recombinant glycoform was detected by radioimmunoassay, indicating that glycosylation is not essential for secretion in Chinese hamster ovary cells. Ligand blotting of the conditioned media using $\left[{ }^{125}\right.$ I]IGF-I indicated that all seven mutants are active. On the basis of the number and molecular masses of the bands detected for each glycoform, there is approximately 4, 4.5
\end{abstract}

and $5 \mathrm{kDa}$ of carbohydrate on $\mathrm{Asn}^{89}, \mathrm{Asn}^{109}$ and $\mathrm{Asn}^{172}$ respectively, with variable occupancy of $\mathrm{Asn}^{172}$. Ternary complex formation by the glycovariants in the presence of ALS and excess IGF-I was not significantly different from that of fully glycosylated recombinant human (rh)IGFBP-3 [ $K_{\mathrm{a}}$ (fully glycosylated) $=12.5 \pm 4 \cdot 11 / \mathrm{nmol}$; mean $K_{\mathrm{a}}$ (all mutants) $\left.=22 \cdot 1 \pm 3.0 \mathrm{l} / \mathrm{nmol}\right]$. In contrast, Asn to Asp substitutions decreased acid-labile subunit (ALS) binding activity. Cell-surface association experiments indicate that glycosylation may influence the partitioning of IGFBP-3 between the extracellular milieu and the cell surface. Therefore, while the carbohydrate units appear to be non-essential to ALS or IGF binding, they may modulate other biological activities of IGFBP-3. Journal of Endocrinology (1999) 160, 379-387

\section{Introduction}

Insulin-like growth factor binding protein-3 (IGFBP-3) is a member of a family of homologous proteins that bind the insulin-like growth factors, IGF-I and IGF-II, with high affinities. When bound to either IGF-I or IGF-II, IGFBP-3 can form a high-molecular-weight complex with the acid-labile subunit (ALS), which represents a tightly regulated source of circulating IGFs (Rajaram et al. 1997). IGFBP-3 has also been shown to have cellular activities such as stimulation and inhibition of cell proliferation (Jones \& Clemmons 1995), induction of apoptosis (Gill et al. 1997, Rajah et al. 1997) and nuclear translocation (Jaques et al. 1997, Li et al. 1997, Schedlich et al. 1998), and it is thought that many of these cellular functions may require the cell-surface association of IGFBP-3.

IGFBP-3 is known to undergo post-translational modification by phosphorylation and glycosylation. Analysis of the human (h)IGFBP-3 cDNA sequence (Wood et al. 1988) predicts the core protein to be 264 amino acids with a molecular mass of approximately 29000 . The amino acid sequence also predicts three potential $\mathrm{N}$-glycosylation sites (Asn-X-Ser/Thr) located at
Asn $^{89}$, Asn $^{109}$ and Asn ${ }^{172}$ (sites 1, 2 and 3 respectively) in the central region, which is not conserved among the IGFBPs. Native hIGFBP-3 is usually found as a characteristic doublet of approximately $40-45 \mathrm{kDa}$, from both cellular and plasma sources. The two natural forms of hIGFBP-3 were demonstrated to be glycoproteins by precipitation with concanavalin $\mathrm{A}$ and by positive staining with periodic acid-Schiff's reagent (Martin \& Baxter 1986). The same characteristic doublet is seen for recombinant protein, rhIGFBP-3, expressed in Chinese hamster ovary (CHO) cells which upon treatment with $\mathrm{N}$-glycanase under reducing conditions produces a single band of approximately $30000 \mathrm{Da}$ (Tressel et al. 1991). This led to the speculation that the doublet consists of two differentially glycosylated forms but the data did not indicate which of the three potential sites were utilised as oligosaccharide acceptor sites. Non-glycosylated rhIGFBP-3 has also been expressed in Escherichia coli, and was shown to be identical to fully glycosylated rhIGFBP-3 from $\mathrm{CHO}$ cells in its IGF-I binding activity (Sommer et al. 1993). Although non-glycosylated rhIGFBP-3 from E. coli has been used extensively in various studies as a pure form of the protein, the role of the carbohydrate chains, either in total or individually, has not been studied 
extensively, and the non-glycosylated protein has not been compared with glycosylated IGFBP-3 from the same cellular source.

The general function of $N$-glycosylation is to aid in the in vivo folding and assembly of the nascent polypeptide chain, maintaining its conformation and directing its ultimate secretion from the cell (Rademacher et al. 1988, Lis \& Sharon 1993). More specifically, carbohydrates on glycoproteins can modulate physicochemical properties and biological activities. For example, it is now well established that correct and complete $\mathrm{N}$-glycosylation of the common $\alpha$ subunits of gonadotrophic hormones such as chorionic gonadotrophin, luteinizing hormone and follicle-stimulating hormone is critical for signal transduction; in the case of human chorionic gonadotrophin, deglycosylated forms bind with greater affinity to the cognate receptor, but are unable to activate adenylate cyclase (Lis \& Sharon 1993, Thotakura \& Blithe 1995).

We have previously shown that the ligand-binding activities of CHO-derived wild-type rhIGFBP-3 are similar to those of pure, plasma-derived hIGFBP-3 (Firth et al. 1998). In a preliminary report, we described a panel of IGFBP-3 cDNA mutants encoding proteins that have lost one, combinations of two or all three of the potential $\mathrm{N}$-glycosylation sites and the expression of the proteins in CHO cells (Firth \& Baxter 1995). In this study, we have compared these recombinant IGFBP-3 glycoforms with fully glycosylated rhIGFBP-3 (also derived from $\mathrm{CHO}$ cells) for their IGF, ALS and cell-surface binding abilities.

\section{Materials and Methods}

\section{Materials}

All radiolabelled proteins used were prepared as described previously (Baxter \& Martin 1986, Baxter et al. 1992). Oligonucleotides were synthesised on an Oligo 1000 DNA Synthesiser (Beckman Instruments, Palo Alto, CA, USA). Restriction and modifying enzymes were purchased from Promega Corp. (Madison, WI, USA) and the T7 Sequencing Kit was purchased from Pharmacia Biotech Inc. (Uppsala, Sweden). Hexadimethrine bromide (Polybrene), dexamethasone, hypoxanthine, xanthine, thymidine, and mycophenolic acid were from Sigma Chemical Co. (St Louis, MO, USA) and aminopterin was purchased from Life Technologies Inc. (Gaithersburg, MD, USA). Nucleoside-free $\alpha$-modified Eagle's medium ( $\alpha$-MEM) and foetal calf serum were from Cytosystems (North Ryde, NSW, Australia). The human IGFBP-3 radioimmunoassay (RIA) has been described previously (Baxter \& Martin 1986). Antiserum R-100 has a higher titre, but similar specificity, compared with the antiserum R1-4.

\section{Site-directed mutagenesis and construction of expression vectors}

The cloning of IGFBP-3 cDNA into both the mutagenesis vector, pSELECT (Promega Corp.), and the expression vector, pMSG (Pharmacia Biotech Inc.), has been described elsewhere (Firth et al. 1998). Using the pSELECT-hIGFBP-3 plasmid as the mutagenesis vector, various combinations of oligonucleotides were used to introduce single, double and triple mutations in vitro, as described previously (Firth et al. 1998). The following oligonucleotides were used for substituting Asn ${ }^{89}$ with Ala or Asp: 5'-GCGGGCTCTGCGTCgcCGCTAGTGCC GTC or 5'-GCGGGCTCTGCGTCgACGCTAGTGC CGTC; substituting Asn ${ }^{109}$ with Ala or Asp: 5'-CGCC AGCTCCAGGAgcTGCTAGTGAGTCG or 5'-CGC CAGCTCCAGGAgATGCTAGTGAGTCG; and substituting Asn ${ }^{172}$ with Ala or Asp: 5'-GCACAGATACCC AGgcCTTCTCCTCCGAG or 5'-GCACAGATACCC AGgACTTCTCCTCCGAG. Nucleotides that differ from the IGFBP-3 sequence are indicated in lowercase letters. The hIGFBP-3 coding sequences of each construct were verified by plasmid DNA sequencing (Tabor \& Richardson 1987), following which each cDNA was amplified and cloned into pMSG as described for wildtype hIGFBP-3 cDNA previously (Firth et al. 1998).

\section{Cell culture and transfection}

CHO cells were grown in $\alpha$-MEM supplemented with $10 \%(\mathrm{v} / \mathrm{v})$ foetal calf serum at $37^{\circ} \mathrm{C}$. For transfection, the cells were plated out at $6 \times 10^{5}$ cells per $75 \mathrm{~cm}^{2}$ flask, incubated for $24 \mathrm{~h}$ and then transfected with $20 \mu \mathrm{g}$ each rhIGFBP-3 expression plasmid or pMSG in the presence of $100 \mu \mathrm{g}$ polybrene (Chaney et al. 1986). The plasmids contain the guanine phosphoribosyltransferase (GPT) gene, gpt, which confers resistance to mycophenolic acid. The transfected cells were cultured in GPT selection medium for 21 days to select for stable transfectants. The medium for GPT selection consisted of $\alpha$-MEM supplemented with $10 \%(\mathrm{v} / \mathrm{v})$ foetal calf serum, $250 \mu \mathrm{g} / \mathrm{ml}$ xanthine, $25 \mu \mathrm{g} / \mathrm{ml}$ mycophenolic acid, $2 \mu \mathrm{g} / \mathrm{ml}$ aminopterin, $10 \mu \mathrm{g} / \mathrm{ml}$ thymidine and $15 \mu \mathrm{g} / \mathrm{ml}$ hypoxanthine. Expression of the recombinant proteins is driven by the mouse mammary tumour virus long terminal repeat (MMTV LTR) promoter on pMSG, which has a glucocorticoid-responsive element, hence expression is inducible by dexamethasone. Following the selection period of 21 days, the mixed population of each transfected cell line was grown to confluence and the media changed to serum-free $\alpha$-MEM supplemented with $0 \cdot 1 \%(\mathrm{w} / \mathrm{v})$ BSA and $10 \mu \mathrm{M}$ dexamethasone. After $72 \mathrm{~h}$, the conditioned media were collected and stored at $-15{ }^{\circ} \mathrm{C}$, before being assayed for rhIGFBP-3 by RIA. Where required, the conditioned media were concentrated by centrifugation through Centriprep-10 concentrators (Amicon Inc., Beverley, MA, USA). At the end of some experiments, total DNA in the cell monolayer was measured by fluorimetry using Hoechst 33258 dye (Calbiochem, La Jolla, CA, USA), as described previously (Labarca \& Paigen 1980). 


\section{Ligand blotting}

Each protein was purified by immunoprecipitation with IGFBP-3 specific antibody bound to Protein-A Sepharose CL-4B (Pharmacia Biotech, Uppsala, Sweden) before electrophoresis. Briefly, approximately $50 \mathrm{ng}$ each protein were incubated with the antibody-Protein-A Sepharose mixture for $2 \mathrm{~h}$ at room temperature. Following extensive

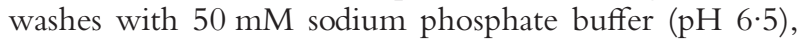
each sample was resuspended in $50 \mu$ Laemmli sample buffer (0.01 M Tris, $\mathrm{pH} 6 \cdot 8,1 \%(\mathrm{w} / \mathrm{v})$ SDS, 10\% (v/v) glycerol), heated at $95{ }^{\circ} \mathrm{C}$ for $5 \mathrm{~min}$ and then electrophoresed on a $12 \%$ SDS-polyacrylamide gel and electroblotted onto nitrocellulose. The blot was incubated with $\left[{ }^{125} \mathrm{I}\right]$ IGF-I $\left(1 \times 10^{6}\right.$ c.p.m. $\left./ 50 \mathrm{ml}\right)$ for $16 \mathrm{~h}$ at $22{ }^{\circ} \mathrm{C}$ and washed as described previously (Firth et al. 1998). The blot was placed against a Storage Phosphor Screen for $16 \mathrm{~h}$ and the image scanned and analysed on a PhosphorImager SP (Molecular Dynamics, Sunnyvale, CA, USA).

\section{ALS binding assays}

ALS binding in the presence of wild-type or variant rhIGFBP-3 was measured as described previously (Baxter et al. 1989). Briefly, $\left[{ }^{125} \mathrm{I}\right]$ ALS (10 000 c.p.m.) was incubated with mixtures of IGF-I (50 ng) and varying concentrations of rhIGFBP-3 or variants (over the range 0-10 ng) in a total volume of $0.3 \mathrm{ml} 50 \mathrm{mM}$ sodium phosphate containing $1 \%(\mathrm{w} / \mathrm{v}) \mathrm{BSA}$ at $22{ }^{\circ} \mathrm{C}$ for $2 \mathrm{~h}$. Ternary complexes were immunoprecipitated with $0.5 \mu \mathrm{l}$ IGFBP-3 antibody and $2.5 \mu \mathrm{l}$ goat anti-rabbit immunoglobulin in the presence of a $4 \%$ final concentration of polyethylene glycol.

The affinity of ALS binding to the rhIGFBP-3-IGF-I binary complex was determined as described previously (Baxter et al. 1992), except that the concentrations of rhIGFBP-3 analogues (1 ng) and IGF-I (50 ng) were held constant, whereas unlabelled ALS was added over the concentration range $2 \cdot 5-200 \mathrm{ng}$ in a total volume of $0.3 \mathrm{ml}$. Bound tracer was separated from free tracer as described above. Scatchard analysis was performed as previously described (Baxter et al. 1992).

\section{Detection of cell-associated IGFBP-3}

Cell-surface association of endogenous rhIGFBP-3 produced by the transfected cell lines was measured by a previously described immunological assay (Martin et al. 1992). Briefly, cells were plated out at $2 \times 10^{4}$ cells per well in 24-well plates for $48 \mathrm{~h}$. Cultures were changed to serum-free media supplemented with $0 \cdot 1 \%(\mathrm{w} / \mathrm{v})$ BSA and incubated for a further $48 \mathrm{~h}$. The cell monolayers were then washed and incubated with either anti-hIGFBP-3 (R-100) or normal rabbit serum (as control for nonspecific effects) diluted $1 / 5000$ in $0.5 \mathrm{ml}$ media. After a 16-h incubation at $22{ }^{\circ} \mathrm{C}$, the cell monolayers were washed again before incubation with $\left[{ }^{125} \mathrm{I}\right]$ Protein A (20 000 c.p.m. in $0.5 \mathrm{ml}$ media) for $2 \mathrm{~h}$. Excess tracer was removed by washing and the cells were solubilised with $0 \cdot 5 \%(\mathrm{w} / \mathrm{v})$ sodium dodecyl sulphate. The cell lysates were collected and radioactivity was determined in a $\gamma$-counter.

\section{Statistical analysis}

Statistical analysis was carried out using StatView 4.02 (Abacus Concepts Inc., Berkeley, CA, USA). Differences between groups of data were evaluated by Fisher's Protected Least Significant Difference test after analysis of variance.

\section{Results}

Construction and expression of IGFBP-3 glycosylation variants

A panel of seven IGFBP-3 analogues was constructed such that the Asn residue of each potential $N$-glycosylation site (Asn-X-Ser/Thr) in IGFBP-3 was substituted with Ala at one, combinations of two, or all three sites, as shown in Fig. 1A. CHO cells were transfected with the plasmid vector, pMSG, or each of the recombinant plasmids. After selection, the transfected cells were expanded and mixed populations of stable transfectants were established. Serum-free media conditioned for $72 \mathrm{~h}$ by each cell line were collected and assayed for hIGFBP-3 by RIA. Although the levels of expression were variable, all seven IGFBP-3 glycosylation variants were detectable (Fig. 1B), suggesting that the process of glycosylation is not required for the secretion of these proteins from $\mathrm{CHO}$ cells. The detection of all the variant proteins by RIA also indicated that our specific polyclonal hIGFBP-3 antibody can recognise both non-glycosylated hIGFBP-3 and its glycoforms. We have previously shown that this antibody recognises an epitope in the amino-terminal portion of IGFBP-3 (Firth et al. 1998), a region without $N$-glycosylation sites. In the IGFBP-3 RIA, whereas rhIGFBP-3 displayed a displacement curve parallel to that of the standard (pure, human serum-derived IGFBP-3), all the glycoforms showed parallel displacement curves up to 1-2 ng/tube, but lost parallelism at greater concentrations (data not shown). Non-parallel displacement curves in the RIA have also been observed for IGFBP-3 fragments (Firth et al. 1998). As the RIA was the only method available for quantifying the proteins, all samples were repeatedly assayed near the midpoint $(1 \cdot 2 \mathrm{ng} /$ tube $)$ of the standard curve.

\section{Estimated molecular masses of the carbohydrate chains on IGFBP-3}

Ligand blotting of the conditioned media using [ $\left.{ }^{125} \mathrm{I}\right] \mathrm{IGF}-\mathrm{I}$ as the ligand indicated that all seven mutants are capable of 
A

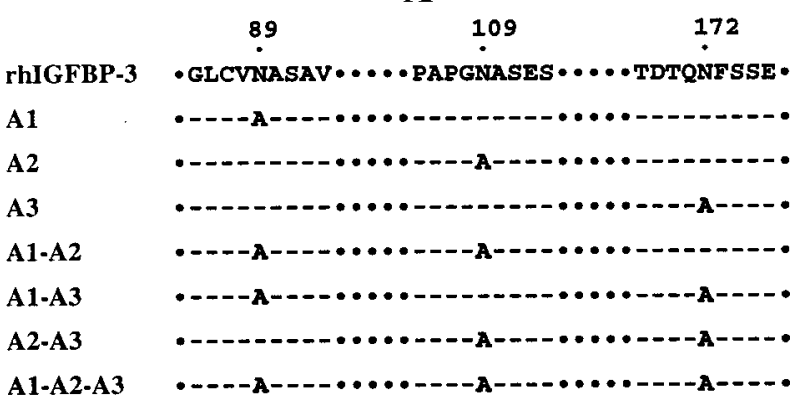

B

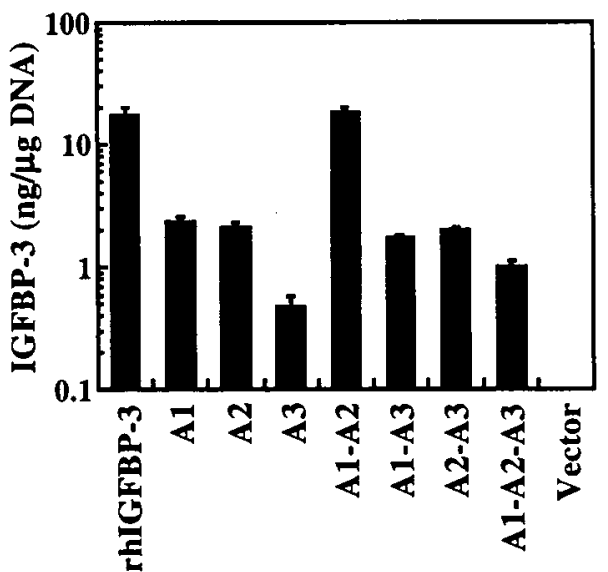

Figure 1 Amino acid sequence of IGFBP-3 N-glycosylation sites and the expression of recombinant IGFBP-3 glycoforms. (A) The sequences surrounding the three potential $\mathrm{N}$-glycosylation sites of IGFBP-3 are shown, with amino acid numbers above. The corresponding sequence of the series of mutants constructed, as described in Materials and Methods, is shown below with the Asn (N) to Ala (A) substitution shown. Dashes indicate residues identical to those of rhIGFBP-3. Nomenclature for the mutant proteins are A1 (Asn ${ }^{89}$ substituted with Ala), A2 (Asn ${ }^{109}$ substituted with Ala) and A3 (Asn ${ }^{172}$ substituted with Ala). (B) Media conditioned by transfected $\mathrm{CHO}$ cells for $72 \mathrm{~h}$ were assayed for IGFBP-3 by RIA. IGFBP-3 concentrations are expressed after correction for DNA content of cells.

binding IGF-I (Fig. 2). Therefore, the carbohydrate chains on IGFBP-3 are not essential for IGF binding. The calculated molecular mass of the core protein of IGFBP-3 is approximately $29 \mathrm{kDa}$, similar to the estimated mass of the A1-A2-A3 mutant (non-glycosylated), which migrated as a single major glycoform of approximately $31.5 \mathrm{kDa}$ (Fig. 2, lane 8). Mutants A1-A3 and A2-A3 also displayed single glycoforms of apparent molecular masses about 36 and $35 \cdot 5 \mathrm{kDa}$ respectively (Fig. 2, lanes 6 and 7). This implies that there are approximately $4 \mathrm{kDa}$ and $4.5 \mathrm{kDa}$ of carbohydrate on $\mathrm{N}$-glycosylation site 1 $\left(\mathrm{N}^{89} \mathrm{AS}\right)$ and site $2\left(\mathrm{~N}^{109} \mathrm{AS}\right)$ respectively. In contrast, there were two glycoforms of A1-A2 (approximately 36.5 and $31.5 \mathrm{kDa}$; Fig. 2, lane 5), suggesting variable

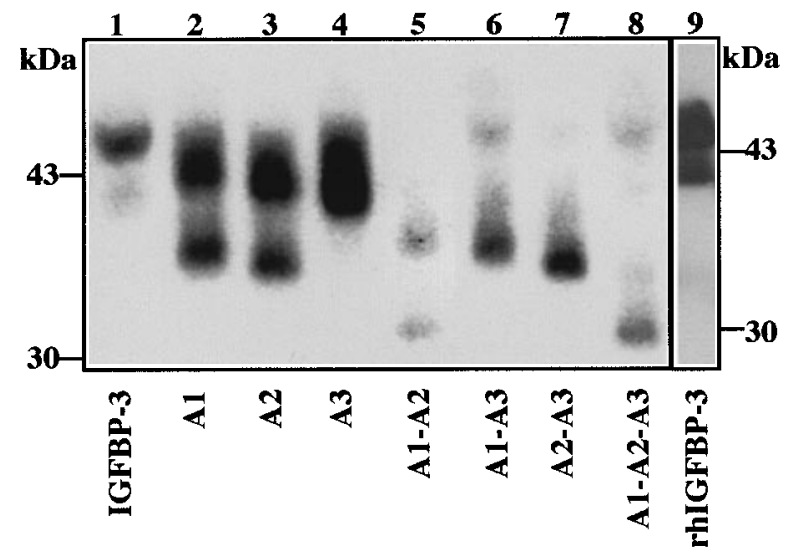

Figure $2\left[{ }^{125}\right.$ I]IGF-I ligand blotting of IGFBP-3 glycoforms. After immunoprecipitation of $50 \mathrm{ng}$ each sample, as described in Materials and Methods, the proteins were electrophoresed on a $12 \%$ SDS-polyacrylamide gel and then transferred to nitrocellulose. The blot was processed for ligand blotting and analysed on a phosphorimager. Samples are purified, serum-derived IGFBP-3 (lane 1), A1 (lane 2), A2 (lane 3), A3 (lane 4), A1-A2 (lane 5), A1-A3 (lane 6), A2-A3 (lane 7) and A1-A2-A3 (lane 8). Relative migration distances of molecular mass standards are indicated on the left of the panel. Purified rhIGFBP-3 (lane 9) was electrophoresed on a separate gel and relative migration distances of molecular mass standards are indicated on the right of the panel. The faint bands seen at about $45 \mathrm{kDa}$ in lanes 6 and 8 are believed to be artefactual, resulting from the very high degree of concentration of culture medium required for these samples.

occupancy at site $3\left(\mathrm{~N}^{172} \mathrm{FS}\right)$. On the basis of the molecular weights of these proteins, there is probably about $5 \mathrm{kDa}$ of oligosaccharides in the larger form, and very little or no carbohydrate on the smaller protein. This notion of variable occupancy at site 3 is supported by the observation that there are invariably two glycoforms of any mutants that have the natural site 3 , as in both mutants A1 (40.5 and $36 \mathrm{kDa}$; Fig. 2, lane 2) and $\mathrm{A} 2(40$ and $35.5 \mathrm{kDa}$; Fig. 2, lane 3) and in natural IGFBP-3 (44.5 and $40 \mathrm{kDa}$; Fig. 2, lane 1). In contrast, a single glycoform is present when site 3 is mutated as in mutants A3, A1-A3, A2-A3 and $\mathrm{A} 1-\mathrm{A} 2-\mathrm{A} 3$ (Fig. 2, lanes 4, 6, 7 and 8 respectively). The faint band at about $45 \mathrm{kDa}$ in lanes $6-8$ is an artefact (possibly CHO IGFBP-3) resulting from the high degree of concentration of these samples. Thus Asn ${ }^{89}$ and Asn ${ }^{109}$ appear to be invariably occupied by glycan chains, suggesting that the two naturally occurring glycoforms of hIGFBP-3, which are invariably seen in the serum and in cell culture medium, are generated by variable glycosylation of Asn ${ }^{172}$.

\section{ALS binding characteristics of IGFBP-3 glycoforms}

The relative abilities of the IGFBP-3 glycoforms to form ternary complexes with ALS in the presence of $50 \mathrm{ng}$ IGF-I are shown in Fig. 3. The dose-response curves of the various glycoforms indicated that the absence of any 


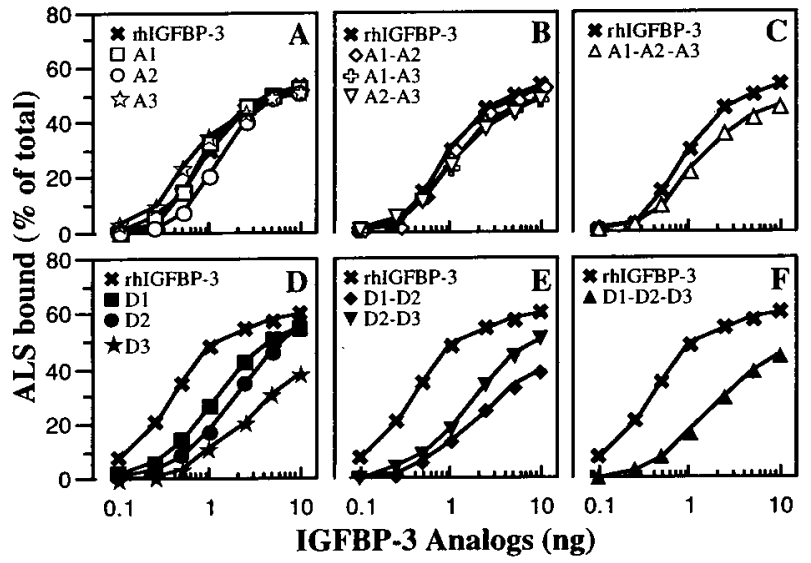

Figure 3 Formation of the ternary complex in the presence of various IGFBP-3 glycoforms. $\left[{ }^{125}\right.$ I]ALS was incubated with increasing amounts of each IGFBP-3 in the presence of excess (50 ng) IGF-I, as described in Materials and Methods. The upper panels (A, B and C) show binding curves for IGFBP-3 glycoforms in which the Asn residue has been substituted with Ala, and the lower panels (D, E, F) show binding curves for IGFBP-3 glycoforms in which the Asn residue has been substituted with Asp. Nomenclature for the mutant proteins is the same as for Fig. 1, except that $\mathrm{D}$ denotes substitution with Asp. The data presented compare single $\mathrm{N}$-glycosylation site mutants (panels $\mathrm{A}$ and $\mathrm{D}$ ), double mutants (panels B and E) and triple mutants (panels $C$ and F) with fully glycosylated rhIGFBP-3. Mutant D1-D3 was excluded from the assay because of insufficient protein. Data are the average of duplicate assay determinants and similar results were obtained in at least one other independent measurement for the Ala mutants.

one (Fig. 3A), two (Fig. 3B) or all three (Fig. 3C) $N$-linked carbohydrates had little effect on ALS binding. In contrast, when the Asn residue of the $N$-glycosylation sites was substituted with Asp instead of Ala, there was a marked decrease in ALS binding (Fig. 3D-F). The double mutant, D1-D3, is not shown in Fig. 3E, as there was insufficient recombinant protein for the assay, because of a very low level of expression.

We determined the displacement of $\left[{ }^{125} \mathrm{I}\right] \mathrm{ALS}$ from ternary complexes formed in the presence of $50 \mathrm{ng}$ IGF-I and 1 ng IGFBP-3 glycoforms, by increasing concentrations of unlabelled ALS. Representative Scatchard plots derived from these binding curves are shown in Fig. 4, with slopes essentially identical for all mutants. The relative affinities of ALS are summarised in Table 1 . Although the association constants for ALS appeared slightly higher in the glycosylation variants compared with rhIGFBP-3, analysis of variance indicated that the association constant was not significantly changed by any mutation $\left(K_{\mathrm{a}}\left(\right.\right.$ rhIGFBP-3) $=12 \cdot 5 \pm 4 \cdot 11 / \mathrm{nmol}$; mean $K_{\mathrm{a}}$ (all mutants) $=22 \cdot 1 \pm 3 \cdot 0 \mathrm{l} / \mathrm{nmol}$ ). There was no statistically significant difference either between rhIGFBP-3 and each glycosylation variant or among the glycosylation variants.

\section{Cell binding characteristics of the IGFBP-3 glycoforms}

The interaction between the endogenously produced IGFBP-3 glycoforms and the cell surface of the $\mathrm{CHO}$ transfectants was examined (Fig. 5). Cells expressing A3 were excluded because later passage cells were no longer secreting the protein. Cell-surface associated forms of all the various glycoforms tested were detectable. To examine the effect of each carbohydrate chain on the distribution of IGFBP-3 between the cell surface and the culture medium, we expressed cell surface binding of each mutant protein as a ratio of the secreted concentration. When the findings were analysed in this way, all but one glycoform (A1-A2) showed significantly more cell-surface association than fully glycosylated IGFBP-3, and the nonglycosylated protein (A1-A2-A3) showed the greatest cell

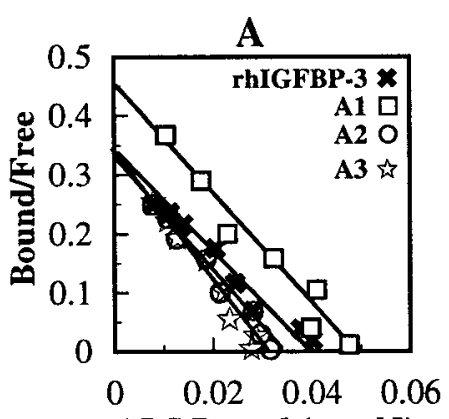

ALS Bound (nmol/l)

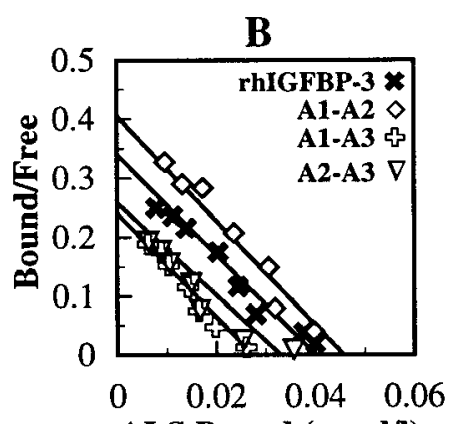

ALS Bound (nmol//)

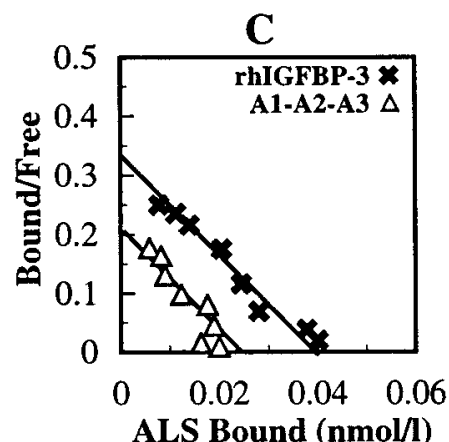

ALS Bound (nmol/l)

Figure 4 Scatchard plots of ALS binding to various IGFBP-3 glycoforms in the presence of excess (50 ng) IGF-I. Competition for the binding of [ $\left.{ }^{125} \mathrm{I}\right] \mathrm{ALS}$ to $1 \mathrm{ng}$ IGFBP-3 by increasing concentrations (2.5-200 ng) of ALS was performed as described in Materials and Methods. Representative Scatchard plots derived from these displacement curves are shown, comparing single $\mathrm{N}$-glycosylation site mutants (panel A), double mutants (panel B) and triple mutants (panel C). Nomenclature for the proteins is the same as in Fig. 1. The plots shown are representatives of three independent measurement for each protein. 
Table 1 Binding parameters for the formation of ternary complexes between IGF-I, ALS, and various glycoforms of IGFBP-3. Ternary complex formation was determined by the binding of [ $\left.{ }^{125} \mathrm{I}\right] \mathrm{ALS}$ to 1 ng each IGFBP-3 analogue in the presence of 50 ng IGF-I. The molecular weight of ALS was taken as 85000 . Values are means \pm S.E.M. for three independent measurements and analysis of variance indicated no significant differences among the various proteins

Association constant $\left(K_{\mathrm{a}}\right)$

$(\mathrm{l} / \mathrm{nmol})$

\begin{tabular}{ll}
\cline { 2 - 2 } $\begin{array}{l}\text { IGFBP-3 } \\
\text { analogue } \\
\text { rhlGFBP-3 }\end{array}$ & $12 \cdot 5 \pm 4 \cdot 1$ \\
A1 & $19 \cdot 6 \pm 5 \cdot 3$ \\
A2 & $24 \cdot 9 \pm 12 \cdot 9$ \\
A3 & $17 \cdot 5 \pm 2 \cdot 8$ \\
A1-A2 & $20 \cdot 1 \pm 6 \cdot 8$ \\
A1-A3 & $22 \cdot 6 \pm 9 \cdot 1$ \\
A2-A3 & $26 \cdot 0 \pm 15 \cdot 1$ \\
A1-A2-A3 & $23 \cdot 8 \pm 6 \cdot 9$
\end{tabular}

binding. We have previously shown that rhIGFBP-3 on the cell surface of $\mathrm{CHO}$ transfectants is displaceable by IGF-I (Firth et al. 1998); similar displacement of the

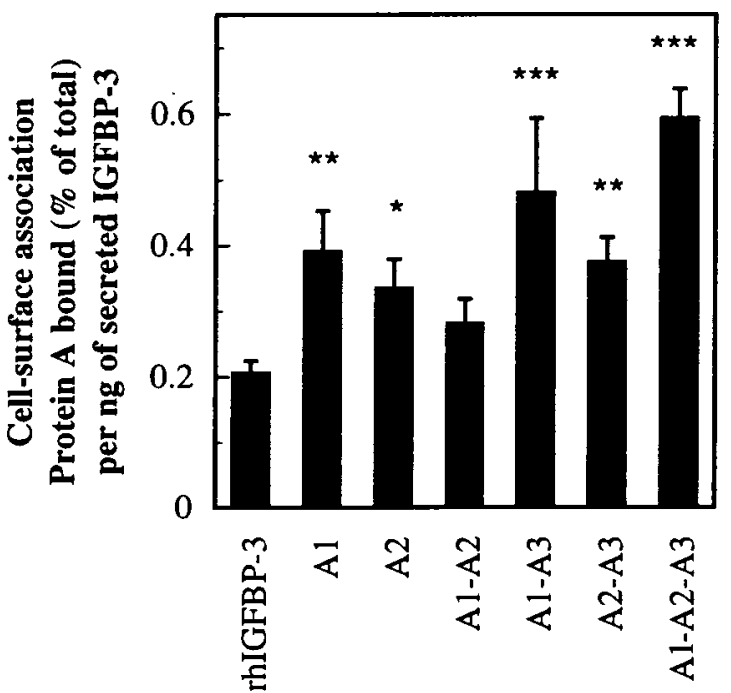

Figure 5 Association of IGFBP-3 glycoforms to the cell surfaces of transfected $\mathrm{CHO}$ cells. Serum-free media conditioned by the cultures of transfected cells were collected and soluble IGFBP-3 determined by RIA. The monolayer cultures of these cells were then incubated with IGFBP-3 antiserum or normal rabbit serum, followed by $\left[{ }^{125} \mathrm{I}\right]$ Protein $\mathrm{A}$ incubation, as described in Materials and Methods. The cells were solubilised and the radioactivity in the cell lysates determined. Specific $\left[{ }^{125}\right.$ I]Protein A binding (minus non-specific binding in the presence of normal rabbit serum) expressed as a percentage of total counts added is indicative of cell-surface associated IGFBP-3. Data shown are ratios of cellsurface associated forms to soluble forms of IGFBP-3 and are the mean \pm S.E. of two independent experiments with triplicate measurements each. Significant effects compared with rhIGFBP-3: ${ }^{*} P<0 \cdot 05,{ }^{*} P<0 \cdot 005$ and ${ }^{* * *} P<0 \cdot 0001$. various IGFBP-3 glycoforms by IGF-I was observed (data not shown).

\section{Discussion}

The post-translational modification of proteins by glycosylation confers heterogeneity resulting in different physical and biochemical properties (for reviews, see Lis \& Sharon 1993, Opdenakker et al. 1993). Carbohydrate units on glycoproteins can regulate the folding, conformation and intracellular traffic and localisation of the protein; they may act as recognition determinants or contribute to binding sites in protein-protein, protein-cell and cell-cell interactions. In addition, they can confer protection against proteolysis and may act as clearance markers and hence determine the lifetime of the glycoprotein in the circulation.

Although non-glycosylated IGFBP-3 expressed in $E$. coli has been used extensively for various studies, the effect of gycosylation either in total or at any one site has not been examined. In this study, we have compared IGFBP-3 glycoforms derived from the same cellular source. The post-translational process of glycosylation does not appear to have a gross effect on the overall folding or assembly of the nascent IGFBP-3 polypeptide or in directing IGFBP-3 secretion from transfected $\mathrm{CHO}$ cells. Although the lack of $N$-glycosylation of IGFBP-3 at any site does not prevent its secretion, subtle effects on secretion cannot be ruled out. Indeed, the difference in expression levels of each recombinant protein may be due to such subtle effects on secretion, differential stability of the recombinant proteins or slight differences in immunoreactivity. However, the levels of recombinant proteins in cell lysates were all lower than the corresponding amount secreted (data not shown), indicating that there is no blockade of secretion.

We have shown that there is approximately $4-5 \mathrm{kDa}$ of carbohydrate at each of the three $\mathrm{N}$-glycosylation sites $\left(A s{ }^{89}, A^{10 n}{ }^{109}\right.$ and $\left.A s n^{172}\right)$. Consistent with the findings in most glycoproteins, the glycosylation at any one site in IGFBP-3 was not dependent on the occupancy of either or both of the other sites. There is variable glycosylation at Asn ${ }^{172}$, which was also not influenced by occupancy or non-occupancy of the other sites. Previous studies have shown that hIGFBP-3 treated with $N$-glycanase under non-reducing conditions resulted in a single band of $37 \mathrm{kDa}$ on SDS-PAGE analysis. The size of the protein decreased further to $30 \mathrm{kDa}$ when deglycosylation was carried out under reducing conditions (Tressel et al. 1991). On the basis of this observation and our finding that the $40-45 \mathrm{kDa}$ fully glycosylated IGFBP-3 is attributable to variable occupancy of $\mathrm{Asn}^{172}$, it would appear that the carbohydrate attachment site at $\mathrm{Asn}^{172}$ is accessible to $N$-glycanase, and that the site at either Asn ${ }^{89}$ or $A_{s n}{ }^{109}$ is not accessible unless the protein is first unfolded. 
Table 2 Predicted glycosylation sites in human IGFBPs-1 to -6

\begin{tabular}{|c|c|c|}
\hline & $N$-glycosylation ${ }^{a}$ & $O$-glycosylation ${ }^{\mathbf{b}}$ \\
\hline IGFBP-1 & - & $\operatorname{Thr}^{27}$, Ser $^{95}$ \\
\hline IGFBP-2 & - & - \\
\hline IGFBP-3 & $\mathrm{Asn}^{89}, \mathrm{Asn}^{109}, \mathrm{Asn}^{172}$ & - \\
\hline IGFBP-4 & $\mathrm{Asn}^{204}$ & - \\
\hline IGFBP-5 & - & Thr ${ }^{103}, \mathrm{Thr}^{104}, \mathrm{Thr}^{111}$ \\
\hline IGFBP-6 & - & $\begin{array}{l}\operatorname{Thr}^{119}, \operatorname{Thr}^{121}, \mathrm{Thr}^{122}, \mathrm{Thr}^{212} \\
\operatorname{Ser}^{120}, \mathrm{Ser}^{124}, \mathrm{Ser}^{208}\end{array}$ \\
\hline
\end{tabular}

aEach IGFBP amino acid sequence was scanned for potential

$\mathrm{N}$-glycosylation sites (Asn-X-Ser/Thr) using ScanProsite (Appel et al. 1994).

botential O-glycosylation sites were predicted using NetOGlyc 2.0 (Hansen et al. 1998).

Among the IGFBPs, only IGFBP-3 and IGFBP-4 have predicted $\mathrm{N}$-glycosylation sites (Table 2 ). The two forms (24 and $28 \mathrm{kDa}$ ) of IGFBP-4, expressed by the rat neuroblastoma cell line, B104, were reduced to $24 \mathrm{kDa}$ when treated with endoglycosidase F (Ceda et al. 1991), thus suggesting variable occupancy at the $\mathrm{N}$-glycosylation site; similar IGFBP-4 glycoforms are also expressed in human cell lines (Durham et al. 1994). Potential O-linked attachment sites are predicted for IGFBPs- 5 and -6 , which are known to be O-glycosylated (Bach et al. 1992, Conover \& Kiefer 1993), and IGFBP-1, which is potentially O-glycosylated, as it was reported to contain $4 \cdot 3 \%$ carbohydrate and did not bind to concanavalin A (Lee et al. 1993). In contrast, there are no predicted O-glycosylation sites on IGFBP-3 and, as the non-glycosylated form (A1-A2-A3) migrated at a molecular mass similar to the predicted mass of the core protein, it appears that the carbohydrate chains of IGFBP-3 are all N-linked.

The binding of $\left[{ }^{125}\right.$ I]IGF-I to all eight IGFBP-3 glycoforms as assessed by ligand blotting suggests that glycosylation per se is not essential for IGF-I binding activity. It is interesting to note that previous studies have shown that the IGF-I binding affinity of non-glycosylated, recombinant IGFBP-3 produced by E. coli is not significantly different from fully glycosylated, recombinant IGFBP-3 derived from transfected CHO cells (Conover 1991, Sommer et al. 1993); therefore, the 'all-or-none' state of glycosylation has no effect on IGF-I binding.

We have previously reported that a highly basic region in the carboxy-terminal region of IGFBP-3 is essential for ALS binding; mutagenesis of this region of IGFBP-3 reduced its ALS affinity by $90 \%$ (Firth et al. 1998). In this study, we have shown that the carbohydrate chains on IGFBP-3 do not actively participate in ALS binding. Furthermore, they do not appear to modulate the ALS binding affinity, as all the different glycoforms displayed similar affinities. When the Asn residue of the $\mathrm{N}$-linked glycosylation sites was substituted with a negatively charged Asp instead of the non-charged Ala, all the glycosylation variants showed five- to tenfold decrease in ALS binding compared with fully glycosylated IGFBP-3.
Given the results obtained with the Ala-containing mutants, this effect is most likely to be due to the introduction of charged Asp residues, rather than to the lack of glycosylation. Assuming that the binding site for ALS is the IGF-I-IGFBP-3 binary complex (Baxter et al. 1992), the decreased ALS binding by the Asp-containing mutants may be secondary to a defect in IGF-I binding. However, a direct effect on ALS affinity is more likely, as ALS interacts with basic residues on IGFBP-3 (Firth et al. 1998), and the addition of negative charge to the binding protein would tend to inhibit this interaction. Regardless of whether the defect lies in IGF-I or ALS binding, it is evident that replacing any one of $\mathrm{Asn}^{89}, \mathrm{Asn}^{109}$ or Asn ${ }^{172}$ with Asp causes a relatively minor change in IGFBP-3, resulting in modulation of affinity rather than abolition of function.

In addition to modulating activity, the carbohydrate chains on glycoproteins may act as recognition determinants in protein-protein and protein-cell interactions (Lis \& Sharon 1993). Besides binding to its ligands (IGF-I and ALS), IGFBP-3 is also known to associate with cell surfaces, and it has been suggested that this form of IGFBP-3 may be involved in cellular actions that occur independently of the IGF-I receptor. Cell-associated forms of IGFBP-3 were present in $\mathrm{CHO}$ cell lines transfected by each glycosylation mutant. This is consistent with our previous observation that an IGFBP-3 variant which has the central, non-conserved region (and hence, the glycosylation sites) deleted is still capable of associating with cell surfaces (Firth et al. 1998). A previous report that recombinant non-glycosylated IGFBP-3 expressed in E. coli can associate with bovine fibroblast cells (Conover 1991) supports this notion. Although the amount of cellassociated IGFBP-3 detected is variable among the glycoforms, the ratios of cell-surface associated protein to soluble protein (secreted into the medium) of the various IGFBP-3 glycoforms are significantly higher $(P<0 \cdot 05)$ than that of fully glycosylated IGFBP-3 with the exception of $\mathrm{A} 1-\mathrm{A} 2(P=0 \cdot 16)$. This would imply that the proportion of IGFBP-3 that is associated with the cell surface is increased with deglycosylation, as seen by the approximately threefold increase in the proportion of cell-associated forms of the non-glycosylated mutant, A1-A2-A3. Therefore, if the extent of glycosylation on IGFBP-3 varies under different physiological conditions, this may well influence the distribution of IGFBP-3 between the circulation, extracellular milieu and cell surfaces. Further studies with preparations of pure IGFBP-3 glycoforms, which will require higher levels of protein expression than are currently available, may provide more insight into this proposed modulatory role of carbohydrates in IGFBP-3.

Considering that one-third of the molecular mass of natural IGFBP-3 consists of carbohydrates, which would have a considerable surface area compared with the protein backbone, it is perhaps surprising that the overall function 
is not affected more substantially by their presence or absence - that is, that they are not absolutely required for any of the functions tested to date. This lack of major effect suggests that the carbohydrates are not essential components of the ligand binding sites on the molecule. In this regard, it is relevant to compare IGFBP-3 with one of the other components of the ternary complex, ALS (Baxter \& Martin 1989), which has approximately $20 \%$ of its molecular mass contributed by carbohydrate (Baxter et al. 1989). We have recently shown that the enzymatic removal of sialic acid from ALS resulted in a two- to threefold decrease in affinity for IGFBP-3, whereas complete deglycosylation of ALS abolished its ability to form ternary complexes (Janosi et al. 1999). It is likely that the sialylation status of ALS modulates its binding affinity by varying the overall negative charge of the molecule; it is known that the interaction between IGFBP-3 and ALS involves charge interactions (Baxter 1990). Further studies of ternary complex formation with various combinations of both IGFBP-3 and ALS glycoforms may give us better understanding of the modulating role of carbohydrates in the ternary complexes.

In summary, all three $N$-glycosylation sites on IGFBP-3 are used as oligosaccharide acceptor sites although there is variable occupancy at $\mathrm{Asn}^{172}$; the process of glycosylation adds approximately 4, 4.5 and $5 \mathrm{kDa}$ at $\mathrm{Asn}^{89}, \mathrm{Asn}^{109}$ and Asn ${ }^{172}$ respectively. Although the carbohydrates are not essential components of the binding sites on IGFBP-3 for IGF-I, ALS or the cell surfaces, the level of glycosylation has the potential to modulate the cell-binding activity of IGFBP-3. It remains to be tested whether the modulatory role of the carbohydrate chains extends to the rates of clearance or protease-susceptibility of IGFBP-3 present in different physiological and pathological conditions.

\section{Acknowledgements}

This study was supported by Project Grant No. 940447 from the National Health and Medical Research Council, Australia.

\section{References}

Appel RD, Bairoch A \& Hochstrasser DF 1994 A new generation of information retrieval tools for biologists: the example of the ExPasy WWW server. Trends in Biochemical Sciences 19 258-260.

Bach LA, Thotakura NR \& Rechler MM 1992 Human insulin-like growth factor binding protein-6 is O-glycosylated. Biochemical and Biophysical Research Communications 186 301-307.

Baxter RC 1990 Glycosaminoglycans inhibit formation of the $140 \mathrm{kDa}$ insulin-like growth factor-binding protein complex. Biochemistry Journal 271 773-777.

Baxter RC \& Martin JL 1986 Radioimmunoassay of growth hormonedependent insulin-like growth factor binding protein in human plasma. Journal of Clinical Investigation 78 1504-1512.

Baxter RC \& Martin JL 1989 Structure of the $M_{\mathrm{r}} 140000$ growth hormone-dependent insulin-like growth factor binding protein complex: determination by reconstitution and affinity-labeling. Proceedings of the National Academy of Sciences of the USA $\mathbf{8 6}$ 6898-6902.

Baxter RC, Martin JL \& Beniac VA 1989 High molecular weight insulin-like growth factor binding protein complex. Purification and properties of the acid-labile subunit from human serum. Journal of Biological Chemistry 264 11843-11848.

Baxter RC, Bayne ML \& Cascieri MA 1992 Structural determinants for binary and ternary complex formation between insulin-like growth factor-I (IGF-I) and IGF binding protein-3. Journal of Biological Chemistry 267 60-65.

Ceda GP, Fielder PJ, Henzel WJ, Louie A, Donovan SM, Hoffman AR \& Rosenfeld RG 1991 Differential effects of insulin-like growth factor (IGF)-I and IGF-II on the expression of IGF binding proteins (IGFBPs) in a rat neuroblastoma cell line: isolation and characterization of two forms of IGFBP-4. Endocrinology 128 2815-2824.

Chaney WG, Howard DR, Pollard JW, Sallustio S \& Stanley P 1986 High-frequency transfection of $\mathrm{CHO}$ cells using polybrene. Somatic Cell and Molecular Genetics 12 237-244.

Conover CA 1991 Glycosylation of insulin-like growth factor binding protein-3 (IGFBP-3) is not required for potentiation of IGF-I action: evidence for processing of cell-bound IGFBP-3. Endocrinology 129 3259-3268.

Conover CA \& Kiefer MC 1993 Regulation and biological effect of endogenous insulin-like growth factor binding protein-5 in human osteoblastic cells. Journal of Clinical Endocrinology and Metabolism 76 1153-1159.

Durham SK, Riggs BL \& Conover CA 1994 The insulin-like growth factor-binding protein-4 (IGFBP-4)-IGFBP-4 protease system in normal human osteoblast-like cells: regulation by transforming growth factor-beta. Journal of Clinical Endocrinology and Metabolism 79 1752-1758.

Firth SM \& Baxter RC 1995 The role of glycosylation in the action of IGFBP-3. Progress in Growth Factor Research 6 223-229.

Firth SM, Ganeshprasad U \& Baxter RC 1998 Structural determinants of ligand and cell surface binding of insulin-like growth factor binding protein-3. Journal of Biological Chemistry 273 2631-2638.

Gill ZP, Perks CM, Newcomb PV \& Holly JMP 1997 Insulin-like growth factor-binding protein (IGFBP-3) predisposes breast cancer cells to programmed cell death in a non-IGF-dependent manner. Journal of Biological Chemistry 272 25602-25607.

Hansen JE, Lund O, Tolstrup N, Gooley AA, Williams KL \& Brunak S 1998 NetOglyc: prediction of mucin-type O-glycosylation sites based on sequence context and surface accessibility. Glycoconjugate Journal 15 115-130.

Janosi JBM, Firth SM, Bond JJ, Baxter RC \& Delhanty PJD 1999 $N$-linked glycosylation and sialylation of the acid-labile subunit: role in complex formation with insulin-like growth factor (IGF) binding protein-3 and the IGFs. Journal of Biological Chemistry (In press).

Jaques G, Noll K, Wegmann B, Witten S, Kogan E, Radulescu RT \& Havemann K 1997 Nuclear localization of insulin-like growth factor binding protein 3 in a lung cancer cell line. Endocrinology 138 $1767-1770$.

Jones JI \& Clemmons DR 1995 Insulin-like growth factors and their binding proteins: biological actions. Endocrine Reviews 16 3-34.

Labarca C \& Paigen K 1980 A simple, rapid, and sensitive DNA assay procedure. Analytical Biochemistry 102 344-352.

Lee PDK, Conover CA \& Powell DR 1993 Regulation and function of insulin-like growth factor-binding protein-1. Proceedings of the Society for Experimental Biology and Medicine 204 4-29.

Li W, Fawcett J, Widmer HR, Fielder PJ, Rabkin R \& Keller G-A 1997 Nuclear transport of insulin-like growth factor-I and insulin-like growth factor binding protein-3 in opossum kidney cells. Endocrinology 138 1763-1766.

Lis H \& Sharon N 1993 Protein glycosylation. Structural and functional aspects. European Journal of Biochemistry 218 1-27. 
Martin JL \& Baxter RC 1986 Insulin-like growth factor binding protein from human plasma. Purification and characterization. Journal of Biological Chemistry 261 8754-8760.

Martin JL, Ballesteros M \& Baxter RC 1992 Insulin-like growth factor-I (IGF-I) and transforming growth factor- $\beta 1$ release IGFbinding protein-3 from human fibroblasts by different mechanisms. Endocrinology 131 1703-1710.

Opdenakker G, Rudd PM, Ponting CP \& Dwek RA 1993 Concepts and principles of glycobiology. FASEB Journal 7 1330-1337.

Rademacher TW, Parekh RB \& Dwek RA 1988 Glycobiology. Annual Reviews of Biochemistry 57 785-838.

Rajah R, Valentinis B \& Cohen P 1997 Insulin like growth factor (IGF)-binding protein-3 induces apoptosis and mediates the effects of transforming growth factor- $\beta 1$ on programmed cell death through a p53- and IGF-independent mechanism. Journal of Biological Chemistry 272 12181-12188.

Rajaram S, Baylink DJ \& Mohan S 1997 Insulin-like growth factorbinding proteins in serum and other biological fluids: regulation and functions. Endocrine Reviews 18 801-831.

Schedlich LJ, Young TF, Firth SM \& Baxter RC 1998 Insulin-like growth factor-binding protein (IGFBP)-3 and IGFBP-5 share a common nuclear transport pathway in T47D human breast carcinoma cells. Journal of Biological Chemistry 273 18347-18352.
Sommer A, Spratt SK, Tatsuno GP, Tressel T, Lee R \& Maack CA 1993 Properties of glycosylated and non-glycosylated human recombinant IGF binding protein-3 (IGFBP-3). Growth Regulation 3 $46-49$.

Tabor S \& Richardson CC 1987 DNA sequence analysis with a modified bacteriophage T7 DNA polymerase. Proceedings of the National Academy of Sciences of the USA 84 4767-4771.

Thotakura NR \& Blithe DL 1995 Glycoprotein hormones: glycobiology of gonadotrophins, thyrotrophin and free alpha subunit. Glycobiology 5 3-10.

Tressel TJ, Tatsuno GP, Spratt K \& Sommer A 1991 Purification and characterization of human recombinant insulin-like growth factor binding protein 3 expressed in Chinese Hamster Ovary cells. Biochemical and Biophysical Research Communications $\mathbf{1 7 8}$ 625-633.

Wood WI, Cachianes G, Henzel WJ, Winslow GA, Spencer SA, Hellmiss R, Martin JL \& Baxter RC 1988 Cloning and expression of the growth hormone-dependent insulin-like growth factor-binding protein. Molecular Endocrinology 2 1176-1185.

Received 30 July 1998

Accepted 23 October 1998 